general articles and lectures in which he displayed his masterly grasp of, and wide-ranging thinking about, microbial physiology, and are written in his characteristically vivid personal style. In these writings Kluyver established himself as a great thinker and teacher about microbiology : the experimenter who related his findings to the advance of his field of science as a whole. Every one of these papers should be read and digested by anyone who is concerned with the future trends of microbiological science and its mode of progress.

Part 3. Bibliography and addenda (pp. 527-563). This contains detailed lists of joint papers by Kluyver and co-workers, of doctoral theses supervised by him, of papers from the laboratories at Delft and Utrecht which he influenced; lists also of the members of the staff at Delft during Kluyver's directorship, of the many honours conferred upon him, and of obituary articles. This simple documentation of his work and influence strikingly illustrates his energy and breadth of interests.

Kluyver was a splendid man and a splendid scientist of the kind most fitted to this epoch. He was never content only to deepen his studies of microorganisms, but was always conscious of, and able to explain clearly, the relations of the work of his school to the advance of microbiology as a whole. His work and influence continue to shape that science. What better memorial could a man wish than that people will roturn again and again to his writings to seek refreshment and inspiration. This beautiful volume should be possessed by every university library and every department of biological science.

B. C. J. G. KNIGHT

\section{DIAGNOSIS OF HUMAN GROWTH}

\section{Growth Diagnosis}

Selected Methods for Interpreting and Predicting Physical Development from One Year to Maturity. By Leona M. Bayer and Nancy Bayley. Pp, xiv +241 . (Chicago : University of Chicago Press ; London : Cambridge University Press, 1959.) 10 dollars ; 80s. net.

$\mathrm{P}$ HYSICIANS concerned with the treatment of children and adolescents will be glad to see a book which provides them with a set of blue-prints for assessing growth. In a number of research centres, and particularly in the United States, the individual progress of hundreds of boys and girls has been documented from birth to maturity. Based on these studies, the details of growth have been precisely delineated to show increases in individual parameters and changes in proportions as well as in certain more superficial and subtle aspects of body covering and contour.

Since deviations in growth pattern may reflect corresponding physiological a.bnormalities, accurate recognition of deviations can be an important diagnostic aid. An exact description of the morphological and temporal aspects of a growth deviation may thus provide a reliable guide to its probable ætiology.

Before establishing deviations, however, it is necessary to define norms, and this the authors do by selecting examples from a population which is ethnically homogeneous, clearly described and numerically adequate; the norms can also be statistically defined. These anthropometric norms have been derived mainly from American children of European origin who have been nurtured under favourable conditions ; in most cases they have been expressed in means and standard deviations.

The great value of this book is that it is very practical. Elaborations of anthropometric measures and indices are limited to five each, and have been chosen for their simplicity and for their usefulness over the whole span of childhood and adolescence and for their special relevance to sexual differentiations. Most physicians wishing to make use of the extensive lists of charts and tables should be prepared to take three measurements in addition to the conventional heights and weights.

Although a different presentation might have been required, it is unfortunate that Prof. Bayer and Dr. Bayley have not rounded off such an eminently useful work by the inclusion of relevant information for babies up to the age of one. This is the age-group which commands greatest interest and which could act as a starting point whereby British physicians might take a greater interest in the subject of growth diagnosis.

This look would be appreciated by members of school medical services, maternity and child welfare officers, general practitioners, Service and industrial medical officers, and all students of human biology who are interested in promoting the positive health of children and teenagers.

K. M. HaWkins

\section{RED, ROE AND FALLOW}

\section{Wild Deer}

By A. J. de Nahlik. Pp. $240+26$ plates. (London : Faber and Faber, Ltd., 1959.) 70s. net.

$\mathrm{N}$ the past five or six years there has been a great increase in interest in the wild deer of Britain, both by naturalists and by sportsmen. The Deer Group of the Mammal Society of the British Isles focuses the naturalists' interest and the St. Hubert Club the sporting interest. Squadron-Leader de Nahlik is a member of both, and his book links the two interests, but leaning rather on the sporting side.

He confines himself to three species out of the five or six that are at present running wild in British woods, namely, the native red and roe deer and the probably introduced fallow. The three aliens which he ignores are the widespread sika, the locally common (in the Midlands) muntjac or barking deer, and the much more local Chinese water deer. The book is the fruit of many years field experience of deer, both in Britain and on the Continent, and no doubt the reason that the sika and muntjac are omitted is because the author has not wished to write about animals of which he has no personal experience.

Into the natural history of the red, roe and fallow the author goes reasonably fully, dealing especially with their annual breeding cycle, antlers and how to recognize them at various stages of their development. He tackles next the problem of damage by deer to farming and forestry, and the various methods of control, including the use of chemical repellents. These last have been much more fully investigated on the Continent than in Britain, and it is most useful to have a full list of them, their uses and manufacturers, for the first time in any book on British deer. Other chapters discuss the various niceties of deer shooting and stalking, and so are of less interest to the natural- 